\title{
Pelatihan Pembuatan Media Pembelajaran Berbasis E-Learning bagi Pengajar di Lembaga Pendidikan Luar Sekolah
}

\author{
Training on Making E-Learning-Based Learning Media for Teachers at Non-School Education \\ Institutions
}

\begin{abstract}
A'am Rifaldi Khunaifi*
Arif Supriyadi

Bayu Suratmoko

Department of Elementary Teacher Education, Universitas Muhammadiyah Palangkaraya, Palangka Raya, Central Kalimantan, Indonesia

email: aamrifaldi@gmail.com

\section{Kata Kunci}

E-learning

Media pembelajaran

Pelatihan

Keywords:

E-learning

Learning Media

Training

Received: December 2020

Accepted: January 2021

Published: February 2021

Abstrak

Pesatnya perkembangan teknologi informasi dan komunikasi atau yang dikenal dengan istilah Information and Communication Technology (ICT) telah merambah berbagai bidang kehidupan tidak terkecuali bidang pendidikan dan pengajaran. Berkaitan dengan pembelajaran, pemanfaatan teknologi informasi dalam hal ini e-learning diperlukan tidak hanya pendidik yang terampil me-manfaatkan teknologi serta teknologi untuk pembuatan bahan ajar, akan tetapi diperlukan suatu rancangan agar dapat melaksanakan pembelajaran dengan efektif. Dalam sebuah rancangan pembelajaran (desain instruksional) terdapat suatu proses untuk memandu pelaku (aktor) untuk mendesain, mengembangkan, menerapkan konten e-learning dengan memanfaatkan infrastruktur dan aplikasi e-learning yang tersedia. Pada tahap selanjutnya dalam implementasi e-learning terdapat tahap evaluasi yang dimanfaatkan untuk merevisi atau penyesuaian terhadap tahap-tahap sebelumnya.Suatu lembaga pendidikan yang baik pastilah mengembangkan pengajar dengan menyediakan berbagai fasilitas untuk mendukung proses belajar dan mengajar. Pengajar bisa menggantikannya dengan metode yang baru berupa video ataupun audio yang telah digabungkan dengan bahan ajar yang ingin disampaikan. Seiring berkembangnya teknologi, e-Learning versi mobile atau smartphone dapat kompatibel dengan fitur-fitur yang tersedia pada pembelajaran konvensional sehingga kualitas konten berupa materi pelajaran dapat diakses dengan baik.

Abstract

The rapid development of information and communication technology or what is known as Information and Communication Technology (ICT) has penetrated various fields of life, including education and teaching. With regard to learning, the use of information technology, in this case, elearning, is needed not only for educators who are skilled at utilizing technology and technology for the manufacture of teaching materials, but a design is needed to carry out learning effectively. In a learning design (instructional design) there is a process to guide actors (actors) to design, develop, implement e-learning content by utilizing the available elearning infrastructure and applications. At the next stage in the implementation of e-learning, there is an evaluation stage which is used to revise or adjust to the previous stages. A good educational institution must develop teachers by providing various facilities to support the teaching and learning process. Teachers can replace it with a new method in the form of video or audio that has been combined with the teaching material they want to convey. As technology develops, mobile or smartphone versions of e-Learning can be compatible with the features available in conventional learning so that the quality of content in the form of subject matter can be accessed properly.
\end{abstract}




\section{PENDAHULUAN}

Pendidikan luar sekolah adalah pendidikan yang dirancang untuk membelajarkan siswa agar mempunyai jenis keterampilan dan atau pengetahuan serta pengalaman yang dilaksanakan. di luar jalur pendidikan formal (persekolahan) (Syamsi, 2010). Salah satu lembaga pendidikan luar sekolah adalah bimbingan belajar. Pesatnya perkembangan teknologi informasi dan komunikasi atau yang dikenal dengan istilah Information and Communication Technology (ICT) telah merambah berbagai bidang kehidupan tidak terkecuali bidang pendidikan dan pengajaran. Di sisi lain dengan adanya ICT proses belajar dapat dilakukan kapan saja tanpa terikat ruang dan waktu (Budiman, 2017).

Terdapat lima pergeseran dalam proses pembelajaran dengan berkembangnya penggunaan teknologi informasi yaitu, dari pelatihan ke penampilan, dari ruang kelas ke di mana dan kapan saja, dari kertas ke "online" atau saluran, dari fasilitas fisik ke fasilitas jaringan kerja, dari waktu siklus ke waktu nyata (Gunawan, 2014). Dari studi-studi yang ada, pembelajaran berbasis komputer (courseware) bila dibuat dengan baik terbukti dapat meningkatkan proses belajar pada diri seseorang (Jauhari \& Ibrahim, 2010). Pembelajaran berbantuan komputer telah dapat memberikan nuansa yang berbeda dalam pembelajaran dalam rangka meningkatkan prestasi belajar dan motivasi (Hadade, 2015).

Berkaitan dengan pembelajaran, pemanfaatan teknologi informasi dalam hal ini e-learning diperlukan tidak hanya pendidik yang terampil me-manfaatkan teknologi serta teknologi untuk pembuatan bahan ajar, akan tetapi diperlukan suatu rancangan agar dapat melaksanakan pembelajaran dengan efektif (Hanum, 2013). Dalam sebuah rancangan pembelajaran (desain instruksional) terdapat suatu proses untuk memandu pelaku (aktor) untuk mendesain, mengembangkan, menerapkan konten e-learning dengan me-manfaatkan infrastruktur dan aplikasi e-learning yang tersedia. Pada tahap selanjutnya dalam implementasi e-learning terdapat tahap evaluasi yang dimanfaatkan untuk merevisi atau penyesuaian terhadap tahap-tahap sebelumnya. Desain instruksional merupakan proses dinamis yang dapat berubah-ubah sesuai dengan informasi dan evaluasi yang diterima bertujuan untuk meningkatkan hasil pembelajaran peserta didik sehingga tujuan pembelajaran dapat tercapai (Bariah \& Sidik, 2019).

Suatu lembaga pendidikan yang baik pastilah mengembangkan pengajar dengan menyediakan berbagai fasilitas untuk mendukung proses belajar dan mengajar. Fasilitas tersebut dapat berupa ketersediaan jaringan internet, website yang terintegrasi antara pelajar dan pengajar, serta media mengajar yang memadai seperti PC atau laptop serta proyektor (Setyoningsih, 2015). Jika memang hal - hal tersebut sudah disediakan, maka pengajar bisa mempergunakan fasilitas tersebut untuk membiasakan diri dengan teknologi yang ada dalam proses belajar mengajar. Perlu disadari bahwa kedepannya proses belajar mengajar dapat dilakukan melalui aplikasi e-learning atau mobile browser yang dapat diakses menggunakan koneksi internet (Prabowo et al., 2009). Tidak hanya itu, lembaga pendidikan yang baik juga perlu menyediakan pengembangan profesional untuk para pengajar seperti mengadakan pelatihan dan dukungan teknis seperti yang telah disebutkan untuk pengembangan konten pengajaran dalam mengatasi tantangan metode pengajaran elearning ini agar efektivitas pengajaran dapat terwujud (Mukhtar, 2015).

Pengajar bisa memanfaatkan fasilitas yang ada berupa website yang telah terintegrasi antara pelajar dan pengajar untuk menyampaikan bahan ajarnya. Pengajar dapat memberikan materi pengajaran kepada murid dengan metode lain selain tatap muka secara langsung di 
ruang kelas. Pengajar bisa menggantikannya dengan metode yang baru berupa video ataupun audio yang telah digabungkan dengan bahan ajar yang ingin disampaikan (Yudasmara \& Purnami, 2015). Seiring berkembangnya teknologi, e-learning versi mobile atau smartphone dapat kompatibel dengan fitur-fitur yang tersedia pada pembelajaran konvensional sehingga kualitas konten berupa materi pelajaran dapat diakses dengan baik. E-learning juga dapat dimanfaatkan untuk meningkatkan pemahaman materi dan memperluas sumber materi pengajaran yang ada (Elyas, 2018).

Kegiatan pengabdian pada masyarakat ini dilaksanakan pada lembaga pendidikan luar sekolah yaitu bimbingan belajar Lely Study Club. Di Kota Palangka Raya khususnya telah banyak berdiri mermacam bimbingan belajar yang cukup diminat oleh masyarakat. Berkembangnya kursus seperti bimbingan belajar di satu sisi menunjukkan tingginya antusias anak didik dalam mengupayakan masa depannya. Akan tetapi di sisi lain tumbuh suburnya bimbingan belajar menunjukkan adanya kelemahan dalam sistem pendidikan formal di sekolah. Banyak murid sebagai peserta didik tidak merasa puas dan cukup dengan pendidikan yang mereka jalani di sekolah. Padahal waktu yang mereka habiskan untuk belajar di sekolah tidaklah singkat. Seorang siswa sekolah menengah misalnya rata-rata menghabiskan waktu antara 6-8 jam setiap harinya di sekolah, belum lagi dengan adanya program Pendalaman Materi (PM) yang diselenggarakan oleh pihak sekolah.

Berdasarkan wawancara dengan murid-murid SMA yang pernah mengikuti lembaga bimbingan belajar, menyatakan bahwa lembaga bimbingan belajar memiliki perbedaan dengan sekolah. pada umumnya. Misalnya, segi durasi kegiatan pembelajaran, lembaga bimbingan belajar memiliki durasi yang lebih pendek daripada sekolah pada umumnya, dan segi pemberian materi juga dapat dilihat perbedaannya. Pada kegiatan belajar, peserta didik diajarkan cara-cara (misalkan saja rumus) yang tidak diajarkan di sekolah, yang notabene lebih mudah dicerna oleh memori peserta didiknya dibandingkan.

Untuk mengatasi masalah yang sering terjadi tersebut dan seiring perkembangan teknologi yang canggih, ingin merubah sistem pelaksanaan pembelajaran dan ujian yang konvensional menjadi komputerisasi. Maksudnya disini pelaksanaan pembelajaran secara komputerisasi (Berbasis Komputer) dengan memanfaatkan aplikasi Wondershare Quiz Creator dan Sevima Edlink. Wondershare Quiz Creator adalah sebuah aplikasi yang digunakan dalam pembuatan ujian online atau yang dikenal dengan electronic test dengan cara meng-upload file dari aplikasi di sebuah website kemudian user atau pengguna dapat mengerjakan soal ujian di web dengan memanfaatkan sebuah komputer yang terhubung dengan internet. Sevima EdLink adalah aplikasi berbasis android yang dikhususkan untuk dunia pendidikan dalam membantu dosen/guru menghemat waktu, menjaga kelas tetap teratur, dan meningkatkan komunikasi dengan mahasiswa.

\section{METODOLOGI}

Melihat permasalahan yang dihadapi mitra, maka dibutuhkan langkah-langkah pendekatan yang tepat guna mencapai tujuan dan sasaran dari kegiatan yang akan dilakukan. Metode pendekatan pada program yang dilakukan meliputi:

1. Kegiatan pendataan sarana dan prasana yang dimiliki oleh mitra yang berkaitan dengan kebutuhan kegiatan yang dalam hal ini berkaitan dengan ketersedian jaringan internet yang memadai.

2. Koordinasi antara tim pelaksana kegiatan bersama mitra guna merancang metode pelaksanaan kegiatan pelatihan. 
3. Pelaksanaan kegiatan pelatihan mengenai teknik mendisain dan mengelola media pembelajaran online kepada mitra dalam hal ini kelompok guru di bimbingan belajar dengan menggunakan aplikasi Sevima Edlink dan Wondershare Quiz Creator sehingga kualitas pembelajaran dapat meningkat dan mendukung kebutuhan dalam pelaksanaan pembelajaran.

a. Aplikasi Sevima Edlink

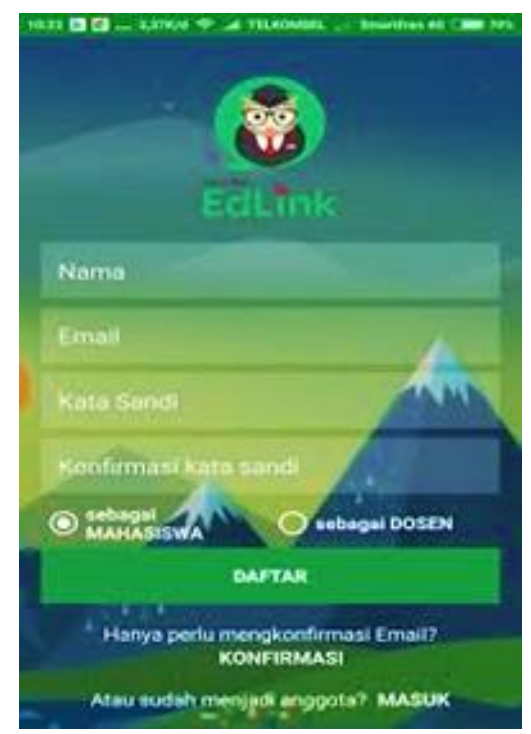

Gambar 1. Langkah Registrasi pada Aplikasi Edlink
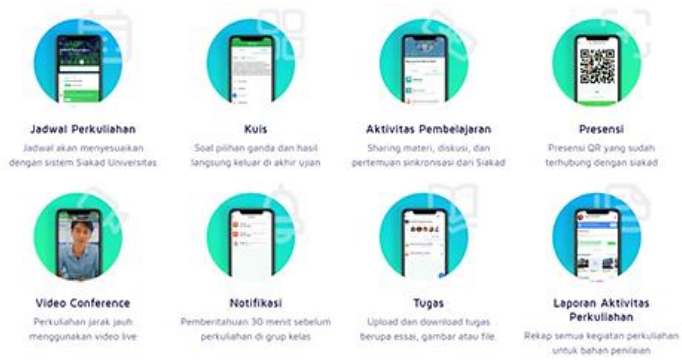

Gambar 2. Fitur pada Aplikasi Edlink

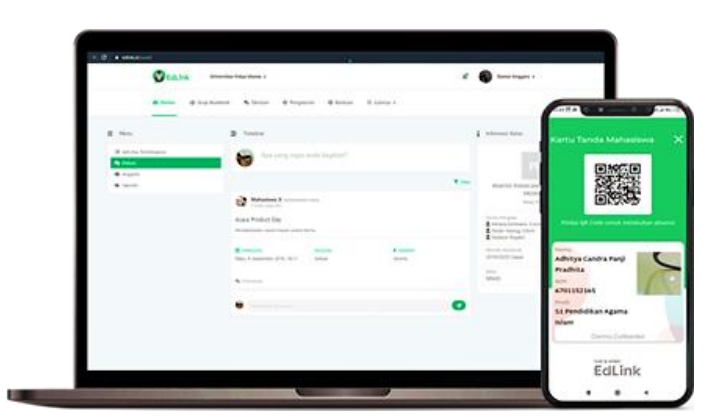

Gambar 3. Proses dalam Pembelajaran Edlink b. Aplikasi Wondershare Quiz Creator

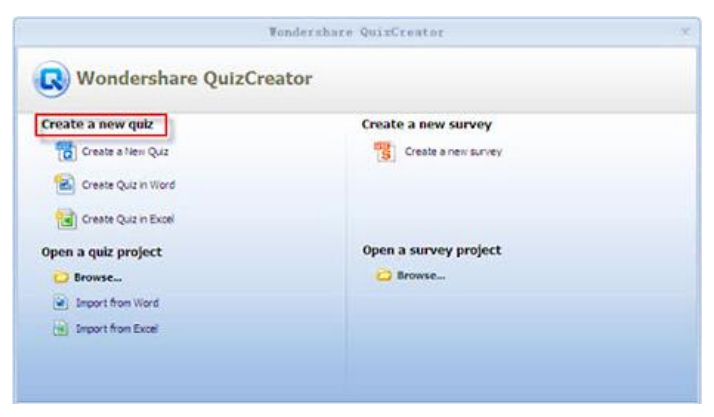

Gambar 4. Langkah Membuat Soal pada Quiz Creator

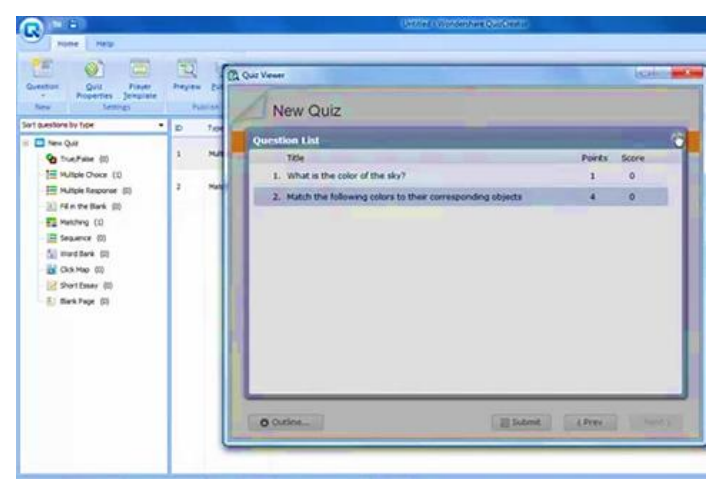

Gambar 5. Proses Memilih Type Soal pada Quiz Creator

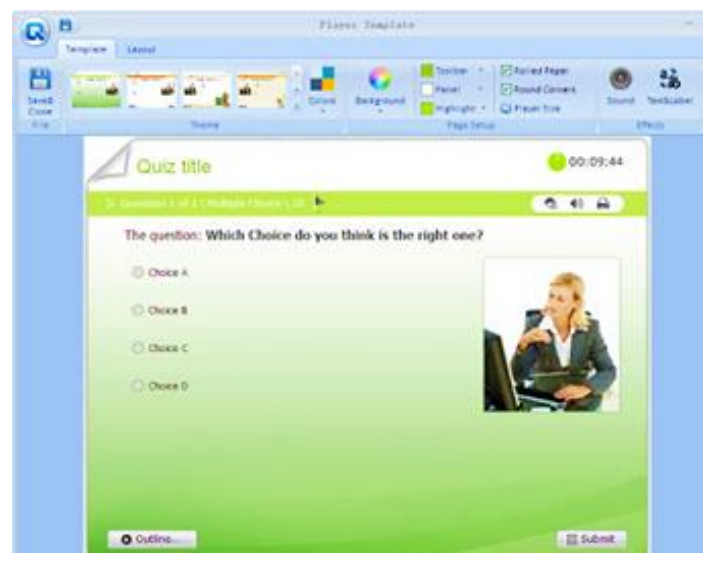

Gambar 6. Preview Soal yang sudah di buat

4. Pengoptimalan penggunaan sarana dan prasarana yang tersedia di lokasi mitra.

5. Memfasilitasi simulasi penggunaan jaringan internet dalam pebelajaran terutama pada pemanfaatan internet sebagai media pembelajaran.

\section{HASIL DAN PEMBAHASAN}

Kegiatan pelatihan ini dilakukan selama 3 hari. Dimulai pada hari Senin 3 Agustus sampai Rabu 5 Agustus 2020. 


\section{Pertemuan Pertama}

Pada pertemuan pada Tanggal 3 Agustus 2020, adapun materi pelatihan pertama ini adalah pelatihan pembuatan media e-learning. Pelaksanaan diisi dengan memberi materi tentang media pembelajaran berbasis e-learning dan langkahlangkah pembuatan media e-learning dengan menggunakan alamat https://edlink.id/. Adapun tujuan kegiatan ini adalah untuk memberikan pengetahuan dasar tentang e-learning kepada peserta, hal ini disebabkan karena sebagian peserta belum mempunyai pengetahuan yang memadai tentang e-learning atau bagaimana cara membuat elearning itu sendiri. Dengan penjelasan secara`detail ini, diharapkan guru paham akan makna dan manfaat serta langkah-langkah pembuatan elearning itu sendiri baik untuk pribadi maupun elearning untuk pembelajaran. Kegiatan selanjutnya, secara tutorial Tim mempraktekan langsung cara membuat e-learning.

\section{Pertemuan Kedua}

Pada pertemuan pada Tanggal 4 Agustus 2020, Pada hari kedua ini peserta akan diberikan materi mengenai pembelajaran berbasis e-learning, diharapkan pada pertemuan ini peserta dapat memahami bagaimana cara menggunakan media elearning yang telah dibuat pada pelatihan pertama. Pada pertemuan yang kedua ini peserta akan di ajarkan cara mengelola kelas, memasukkan bahan ajar dan media sederhana serta membuat kuis soal secara online kedalam website Edlink Sevima elearning yang telah dikembangkan sebelumnya.

3. Pertemuan Ketiga

Pada pertemuan pada Tanggal 5 Agustus 2020, Pada hari ketiga ini peserta akan diberikan materi bagaimana membuat kuis soal secara online yang sederhana, mudah dan menarik dengan menggunakan quiz creator. Aktivitas Peserta Pelatihan antara lain mendengar atau memperhatikan penjelasan TIM pelaksana, membaca modul petunjuk pembuatan media ajar interaktif berbasis blog atau media berbasis elearning, bertanya dengan tim pelaksana tentang materi pelatihan, mengerjakan tugas yang diberikan berdiskusi dengan teman dalam mengerjakan tugas yang diberikan dan prilaku yang tidak releven dengan kegiatan pelatihan (percakapan yang tidak releven, mengerjakan sesuatu yang tidak releven dan melamun).

Berdasarkan hasil observasi selama kegiatan, terlihat bahwa akvitas peserta sangat baik, ini dapat dilihat dari banyaknya indikator-indikator aktivitas pelatihan yang muncul. Begitu juga dengan hasil angket yang diberikan ke peserta diakhir kegiatan, 93\% peserta puas dengan kegiatan ini dan hanya $7 \%$ masih belum puas hal ini disebabkan karena salah satu peserta tersebut tidak mengikuti kegiatan pelatihan pada pertemuan kedua, sehingga peserta tersebut tidak begitu paham dalam membuat animasi yang begerak. Untuk mengatasi masalah ini maka tim meberi saran kepada satu peserta yang belum paham tersebut untuk belajar dengan teman sejawatnya yang sama-sama mengikuti pelatihan ini. Kemudian Tim memberi harapan semoga hasil kegiatan ini dapat diaplikasikan untuk pembelajaran dikelas.

\section{KESIMPULAN}

Berdasarkan sebelum dan selama kegiatan pelatihan, maka dapat diambil kesimpulan bahwa pengajar di Lembaga Pendidikan di luar sekolah khususnya d Lembaga milik Lely Study Club yang menjadi peserta pelatihan pembuatan mediapembelajaran berbasis elearning berhasil membuat media e-learning berbasis modle dengan menggunakan alamat https://edlink.id/, dan pelaksanaan pelatihan telah dapat mencapai tujuan 
yang diharapkan, hal ini dapat dilihat dari tugas-tugas yang diberikan kepada peserta dapat diselesaikan dengan baik.

\section{UCAPAN TERIMA KASIH}

Ucapan terima kasih serta penghargaan sebesarbesarnya tim pelaksana pengabdian yang berjudul “Pelatihan Pembuatan Media Pembelajaran Berbasis ELearning Bgai Pengajar Di Lembaga Pendidikan Luar Sekolah" kepada Lembaga Penelitian dan Pengabdian kepada Masyarakat yang telah mendanai kegaitan ini melalui Hibah Pengabdian Kepada Masyarakat dengan skema PKMS, Direktur Lembaga Bimbingan Belajar Lely Study Club terutama 10 pengajar yang menjadi peserta selama kegiatan pelaksanaan berlangsung, dan Seluruh tim pelaksana pengabdian yang telah banyak membantu untuk mensukseskan kegiatan pengabdian ini.

\section{REFERENSI}

Bariah, S.H., Sidik, S.M. 2019. Penerapan Konten ELearning Berbasis Scorm Untuk Meningkatkan Efektivktas Pembelajaran. Petik: Jurnal Pendidikan Teknologi Informasi dan Komunikasi. $\quad$ 5(1):1-10. https://doi.org/10.31980/jpetik.v5i1.448

Budiman, H. 2017. Peran Teknologi Informasi Dan Komunikasi Dalam Pendidikan. AlTadzkiyyah: Jurnal Pendidikan Islam. 8(1):75-83. https://doi.org/10.24042/atjpi.v8i1.2095

Elyas, A.H. 2018. Penggunaan Model Pembelajaran ELearning Dalam Meningkatkan Kualitas Pembelajaran. Majalah Ilmiah Warta Dharmawangsa. 56:14-24. https://doi.org/10.46576/wdw.v0i56.4

Gunawan, Z. 2014. Pemanfaatan Teknologi Informasi dan Komunikasi (TIK) dalam Pembelajaran. Jurnal Ilmiah Pendidikan Fisika Al-Biruni.3(1):7178. https://doi.org/10.24042/jpifalbiruni.v3i1.67

Hadade, H.I. 2015. Efektivitas Penggunaan Komputer Sebagai Media Presentasi Terhadap
Peningkatan Motivasi Dan Hasil Belajar Dalam Pembelajaran Penjas. Pedagogia: Jurnal Ilmu Pendidikan. 13(3):180-194. https://doi.org/10.17509/pedagogia.v13i3.60 05

Hanum, N.S. 2013. Keefetifan e-learning sebagai media pembelajaran (studi evaluasi model pembelajaran e-learning SMK Telkom Sandhy Putra Purwokerto). Jurnal Pendidikan Vokasi. 3(1):90-102. https://doi.org/10.21831/jpv.v3i1.1584

Jauhari, J., Ibrahim, M.B. 2010. Intelligent Tutoring System sebagai Upaya Inovatif dalam Pembelajaran untuk Pembelajaran Berbantuan Komputer. Jurnal Generic. 5(2):1-6.

Mukhtar. 2015. Strategi Kepala Sekolah Dalam Meningkatkan Kinerja Guru PadaSmp Negeri Di Kecamatan Masjid Raya Kabupaten Aceh Besar. Jurnal Administrasi Pendidikan. 3(3):103117.

Prabowo, R.S., Budi, A., Aryadi, W. 2009. Pembuatan Media Pembelajaran Berbasis Browser Training Dengan Menggunakan Software Content Management System Joomla Pada Mata Diklat Pemeliharaan/Servis Transmisi Manual Dan Komponen. Jurnal Pendidikan Teknik Mesin. 9(2):107-113.

Setyoningsih, S. 2015. E Learning: Pembelajaran Interaktif Berbasis Teknologi Informasi. Elementary: Islamic Teacher Journal. 3(1):39-58. http://dx.doi.org/10.21043/elementary.v3i1. 1443

Syamsi, I. 2010. Pendidikan Luar Sekolah Sebagai Pemberdaya Dalam Masyarakat. Diklus: Jurnal Pendidikan Luar Sekolah. 14(1):66-76.

Yudasmara, G.A., Purnami, D. 2015. Pengembangan Media Pembelajaran Interakif Biologi Untuk Meningkatkan Hasil Belajar Siswa SMP. Jurnal Pendidikan dan Pengajaran. 48(1-3):1-8. http://dx.doi.org/10.23887/jppundiksha.v48 i1-3.6923 